of the humerus and the under surface of the acromion; secondly, in soft, oily, and caseous bones, in which there is a deficiency of phosphatic deposit, a change takes place in the head of the bone, the anatomical neck slides slightly downwards (chiefly in old people), and assumes a rather more lateral aspect than normal, while the inner shell of the bone passes upwards and inwards, and penetrates the cancelli. This, I think there can be no doubt, is the result of the upward pressure against the acromion process. In Sir A. Cooper's case, the tendon is said to have united. With every possible submission to so high an authority, I think he must have meant, that it had become united to the capsule of the joint. The deltoid muscle is not so much affected by the change in the joint as would be expected; occasionally it is slightly atrophied, but the muscle soon again recovers its proper size and tone. Should there appear to be much wasting of it, the surgeon would then have to decide upon the probability of its dependence upon some injury to the posterior circumflex nerve. In this case, sensation over the posterior fold of the axilla and over the insertion of the deltoid would be much impaired." (pp. 150-1.)

In dislocation of the tendon, it may be thrown inwards to the lower part of the joint, or may be lodged either in the greater or lesser tuberosity of the humerus; and it is to be regarded as a more serious accident than rupture.

The treatment of both these accidents is the same, and altogether negative. Entire rest to the joint at first, taking care to bring the elbow forward; and subsequently passive motion, when all chance of inflammation has subsided, constitute all that it is in our power to do.

Fractures of the head of the humerus. This, the last chapter in the book, though sensibly and well written, does not call for much comment. The usual division into fracture of the anatomical and surgical neck, and their occasional complication with dislocation, is adopted by the author. $\mathrm{He}$ also adds a third, of fractures implicating either or both of the tubercles, or in any way comminuting the head of the bone; of which accident two examples are recorded.

Mr. Callaway concludes his modestly-written and instructive essay, by some sensible remarks on the deficiency of an accurate system of hospital reports; and expresses the regret in which all will join at the immense mass of knowledge that is daily running to waste in our hospitals, from the want of some one to collect it.

\title{
ART. XVII.
}

\section{The Treatment of Rheumatic Diseases by Lemon-Juice; with illustrative Cases from Hospital Practice. By G. OWen Rees, M.D., F.R.s., \&c.- London, 1849. 8vo, pp. 38.}

In this little pamphlet Dr. Rees has brought before the notice of the profession the beneficial effects of lemon-juice in acute rheumatic affections. Dr. Rees states that in these cases, lemon-juice in doses of one ounce four or five times a day, appears to be equally efficacious with colchicum, or even more so; it produces an equally rapid reduction in the force and frequency of the pulse, and ensures an earlier relief from pain. In support of these assertions, eight cases of rheumatism are related; and subsequently Dr. Rees proceeds to explain the mode in which the lemon-juice may be supposed to act. The cases seem to have been of moderate severity; in one case only does there appear to have been any cardiac affection, and in that case (VII) there was only a slight systolic murmur at the base. 
The relief to the urgent symptoms seems to have been rapid; although, on adding up the number of days in hospital, we find the average duration of the malady to have been about the same as under other modes of treatment, viz. rather more than twenty-four days ; the longest time was forty-seven, and the shortest twelve days. The most marked effects were on the pulse, which often was lowered six, eight, or ten beats in twenty-four hours. The influence on the urine was not so decided; the solids excreted in twenty-four hours were in one case augmented during its use, in another diminished; the urine was generally acid, and in one case became acid under the use of lemon-juice, although it had previously been alkaline. The acid perspirations do not seem to have been affected. No examination of the blood, or analyses of the urine, appear to have been made; and the cases are so briefly detailed, that we do not learn much more from them except the main fact that the patients got well while taking lemon-juice. We cannot help remarking, that we are sorry Dr. Rees should not have been a little more minute in his chemical observations; for in regard to the pathology of rheumatism, the examination of the blood, the urine, and the sweat is the great subject for inquiry; and probably there is no man in London who is more competent to undertake this investigation than Dr. Rees. We must confess to no little disappointment when we found those important topics so briefly treated in the pamphlet before us.

Dr. Rees's theory of the action of lemon-juice appears to be founded on the notion of Liebig, that urea may be formed from the oxidation of uric acid. Dr. Rees seems to consider retained uric acid as the materies morbi in rheumatism; and thinks that the citric acid $\left(\mathrm{C}_{4}, \mathrm{H}_{2}, \mathrm{O}_{14}\right)$ of the lemon-juice yields oxygen, which, with the elements of water, converts uric acid into urea and carbonic acid. Nothing, however, is more doubtful than this Liebigian hypothesis; and one of Dr. Rees's own colleagues has pointed out its probable fallacies. We would suggest to Dr. Rees an accurate determination of the absolute quantity of urea and uric acid excreted in acute rheumatism; it is evidently a condition of his hypothesis that the quantity of urea shall be relatively much below that of the uric acid, since the mode in which the uric acid comes to be in excess, is by reason of the failure in the process by which, according to Liebig, it is converted into urea. But we shall not be surprised to find analyses proving the urea to be even in excess in rheumatism, either in the blood or the urine. Again, to prove his position Dr. Rees should have brought forward evidence to show an increase in the quantity of urea after the use of lemon-juice; but this has not been done.-We should, however, say that our author expressly states that he considers his hypothesis extremely doubtful, and attaches no importance to it; while he earnestly calls the attention of the profession to the practical fact of the utility of lemon-juice in rheumatism, from whatever cause this good effect may arise. We also attach much more importance to this fact than to its interpretation; and from some little experience of lemon-juice in rheumatism, we are inclined to agree with Dr. Rees in believing it to be of some efficacy, although the amount of this has not been so great in our cases as in those of Dr. Rees. But with the strong opinion which has been given in favour of lemon-juice by Dr. Rees, we have not the slightest hesitation in urging our professional brethren to give it a fair trial in rheumatism, in the belief that it will be found at any rate a useful auxiliary, if not an absolute and certain specific. 